\title{
Partial Length as a Replacement for Total Length in Measuring Grenadiers
}

\author{
D. B. Atkinson \\ Department of Fisheries and Oceans, Research and Resource Services \\ P. O. Box 5667, St. John's, Newfoundland, Canada A1C 5X1
}

\begin{abstract}
The problem of tail breakage and regeneration in grenadiers instigated the initiation of studies to find a suitable partial length measurement as a replacement for the traditional total length measurement. Studies undertaken in 1978 and 1979 on roundnose grenadier, Coryphaenoides rupestris, indicated that the partial length mesurements, pre-anus length and anal-fin length, were highly correlated with total length. The anal-fin length was considered to be more practical than pre-anus length, as the latter is sometimes affected by distortion of the anus due to air-bladder expansion and extrusion of intestines when the fish are brought to the surface from deep water. Consequently, the Scientific Council of NAFO at its meeting in June 1980 adopted anal-fin length (tip of snout to base of first anal fin ray) as the standard for measuring roundnose and roughhead grenadiers.
\end{abstract}

\section{Introduction}

Studies on the biology and population dynamics of roundnose grenadier, $C$. rupestris, have been hampered by the problem of tail breakage and regeneration, resulting in an inability to obtain consistently reliable total length measurements. The alternative has been to examine only those individuals deemed to have complete tails, a decision which may vary from one researcher to another and thus introduce bias into length frequency distributions and the resultant estimates of population structure. With the commencement of a directed fishery for this species in the Northwest Atlantic in 1967 and the subsequent need for continual monitoring and evaluation of the stocks, researchers were encouraged to investigate other suitable length measurements (ICNAF, 1976).

Jensen (MS 1976) noted the problem of tail breakage and suggested that roundnose grenadier be measured from the tip of the snout to the beginning of the anal fin. He presented a formula for converting this partial length (referred to hereafter as anal-fin length) to total length, based on the measurement of 147 specimens collected from Subarea 1 in 1976 . He pointed out that, although the conversion factor could be used for assessment work, it would be simpler to use the partial length directly. He also suggested that an appropriate grouping of these partial lengths would be by $0.5 \mathrm{~cm}$ intervals, in contrast to the $3-\mathrm{cm}$ intervals used for reporting length frequencies based on total length.

Parsons et al. (MS 1978) again indicated the problem of broken and regenerated tails in obtaining representative total length measurements of roundnose grenadier and strongly urged the adoption of a partial length measurement based preferably on anal-fin length. They also noted that the size range of the species was greater than that reported by Jensen (MS 1976) and that measurements were required over a more complete size range to obtain a reliable conversion factor. Further studies by Atkinson (MS 1979), Messtorff and Koch (MS 1979), and Maxim et al. (MS 1979 ) indicated the desirability of using anal-fin length or some other partial length instead of total length for grenadiers, as most of the specimens in trawl catches had broken tails.

ICNAF's Standing Committee on Research and Statistics reviewed all of the above-noted papers at its meeting in June 1979 (ICNAF, 1979), acknowledged that a partial length measurement for roundnose grenadier would be appropriate provided that it was highly correlated with total length, and recommended that detailed studies to clarify the situation should be undertaken and documented as soon as possible. The purpose of this paper is to present the results of Canadian investigations in this regard.

\section{Materials and Methods}

In 1978, scientists of the Northwest Atlantic Fisheries Center, St. John's, initiated the practice of measuring the length of roundnose grenadier as analfin length (tip of snout to base of first anal-fin ray). For specimens with complete tails (unbroken and unregenerated), both total length and anal-fin length were recorded to the nearest millimeter. All measurements were recorded separately by sex.

During otter-trawl (3- $\mathrm{mm}$ mesh liner in codend) surveys at depths of 550-1,200 $\mathrm{m}$ in NAFO Divisions $2 \mathrm{~J}$ and $3 \mathrm{~K}$ in 1978 and 1979, length measurments (anal-fin 


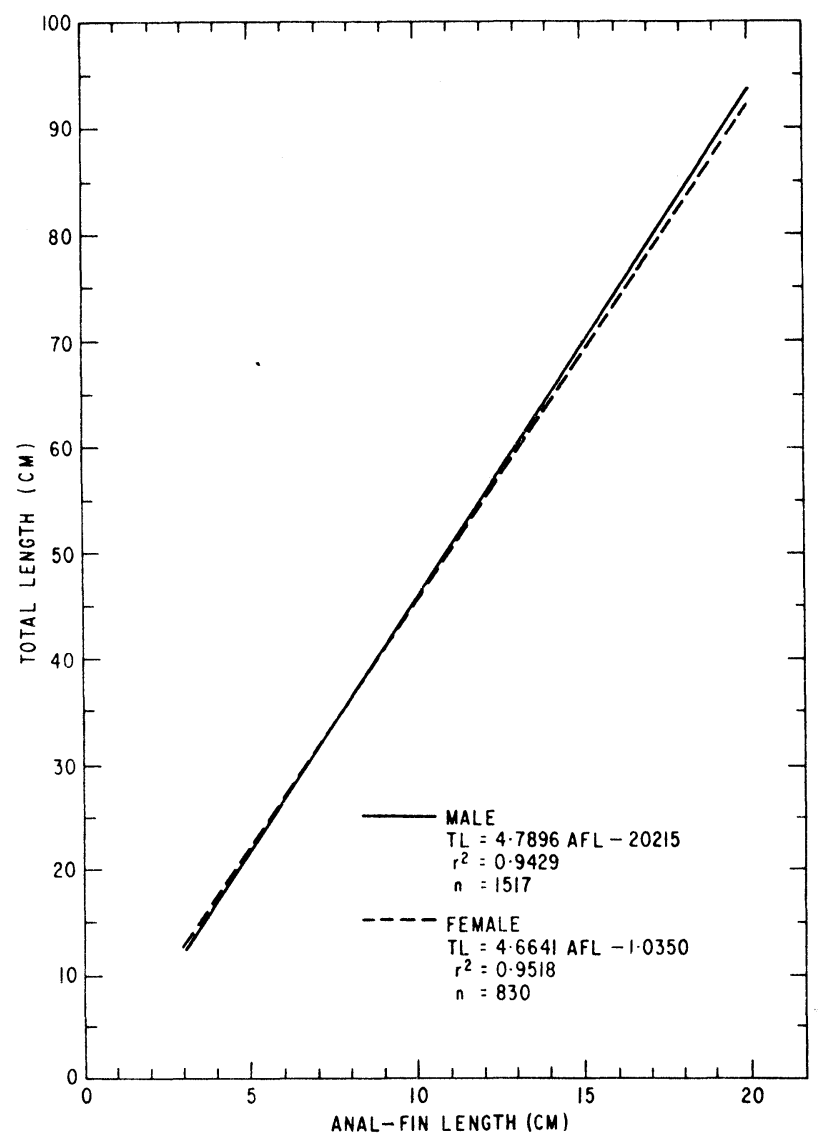

Fig. 1. Relationship between total length and anal-fin length for male and female roundnose grenadier in the LabradorNewfoundland area.

and total) were taken for 2,347 roundnose grenadier (1,517 males and 830 females), which were judged to have complete tails. The total length ranges of the specimens sampled were $13-86 \mathrm{~cm}$ for males and 12-97 cm for females. Also, during the 1979 survey, for comparison with previous work on the relationship between pre-anus length (tip of snout to anterior edge of anus) and total length (Messtorff and Koch, MS 1979), pre-anus length and anal-fin length were recorded for most of the roundnose grenadier caught regardless of tail condition. A total of 8,565 specimens were measured in this manner, the anal-fin length range being 5-20 cm for males and $6-21 \mathrm{~cm}$ for females.

Linear regression analyses were performed on the two sets of data and F-tests were used to test the significance of the relationships.

\section{Results}

Total length was found to be highly correlated with anal-fin length for both male and female grenadier, the

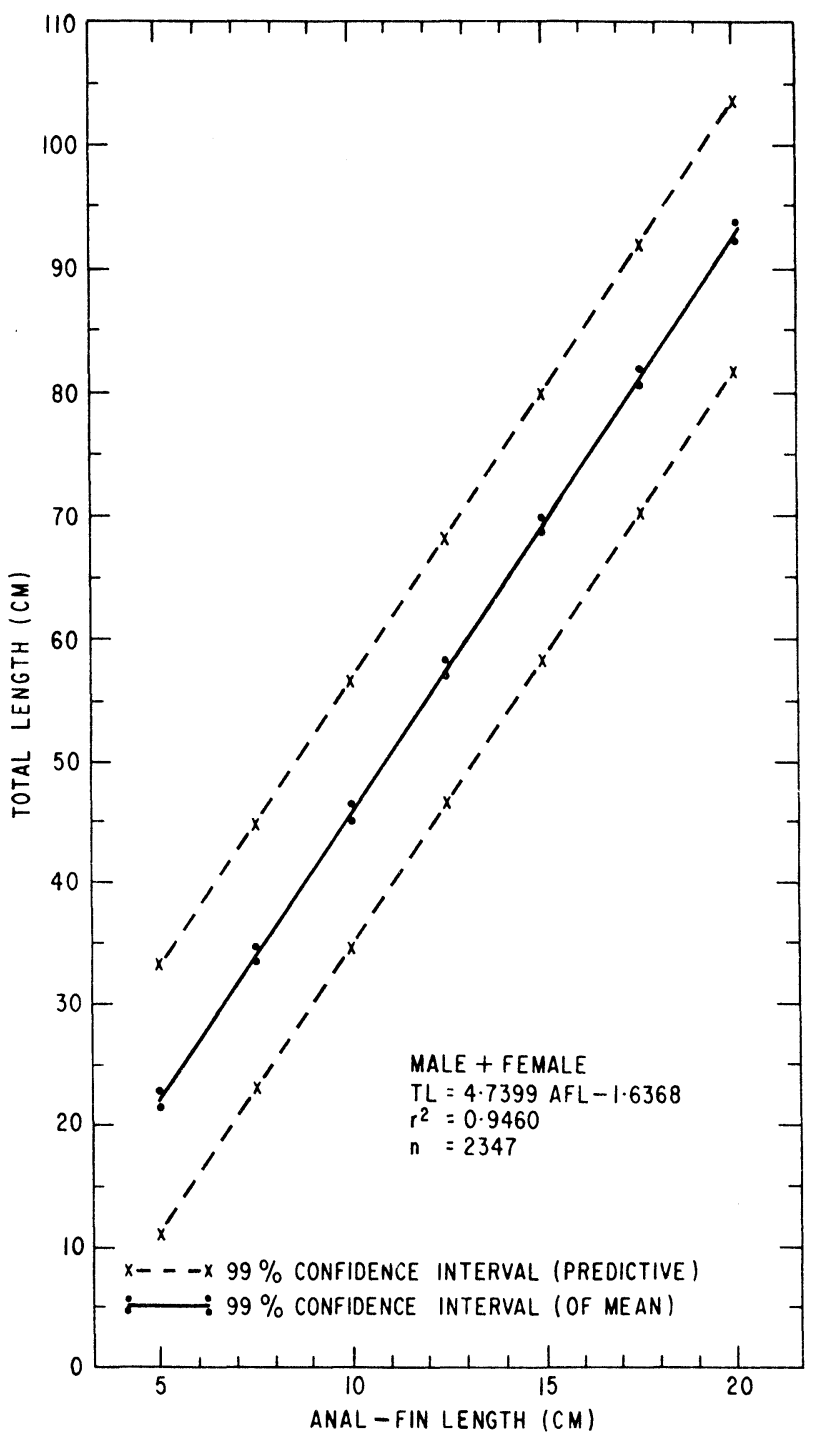

Fig. 2. Relationship between total length and anal-fin length for roundnose grenadier (sexes combined) in the LabradorNewfoundland area.

correlation coefficients ( $r$ ) being 0.971 and 0.976 respectively (Fig. 1). Although the regression coefficients (slopes) for males and females differed significantly $(P<0.05)$ due to the large numbers of fish sampled, the two regression lines were considered to be essentially the same for practical purposes, because a difference of only $1.5 \mathrm{~cm}$ in total length is predicted for an anal-fin length of $20 \mathrm{~cm}$. This difference is just one-half of the 3-cm length interval used in reporting length frequencies of roundnose grenadier, based on total length measurements.

The regression line based on the combined data for males and females (Fig. 2) indicates a high correlation between total length and anal-fin length $(r=$ 0.973 ), with very narrow confidence intervals associated with the expected value of total length for a 


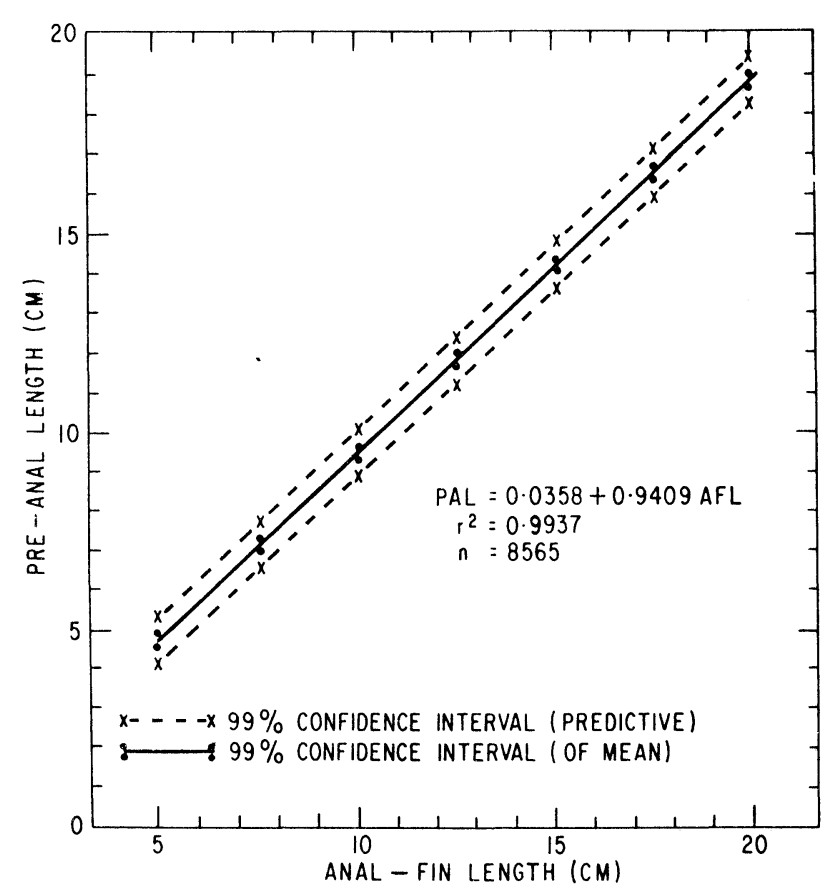

Fig. 3. Relationship between pre-anal length and anal-fin length for roundnose grenadier in the Labrador-Newfoundland area.

given mean anal-fin length and with the predicted value of total length for a given anal-fin length. The regression of pre-anus length on anal-fin length (Fig. 3) also has a high correlation coefficient $(r=0.997)$ with very narrow $99 \%$ confidence intervals. The F-test, in all cases, indicated that the correlations were highly significant $(P<0.01)$.

\section{Discussion}

The results of this study show that there is a highly significant correlation between anal-fin length and total length for roundnose grenadier in Div. $2 \mathrm{~J}$ and $3 \mathrm{~K}$. Also, since a highly significant correlation exists between pre-anus length and anal-fin length, it may be inferred that a significant correlation exists between pre-anus length and total length. This is supported by Kosswig's (MS 1980) study on roundnose grenadier in Subarea 1. Comparison of the relationship between total length and anal-fin length in this paper (Fig. 2) with a similar relationship derived from Kosswig's (MS 1980) equation, using the relationship between preanus length and anal-fin length derived in this paper (Fig. 3), indicates a difference of approximately $4 \mathrm{~cm}$ in total length at the upper limit of anal-fin length (Fig. 4). Although Kosswig's (MS 1980) sample was taken in a different area from that encompassed in the present study, it is more likely that the slight difference in the slopes of the lines is due to the scarcity of large fish in his sample, as he noted "that the line must be supplemented ... above all with length data of bigger fish". Importantly, investigations (Jensen, MS 1976; Mes-

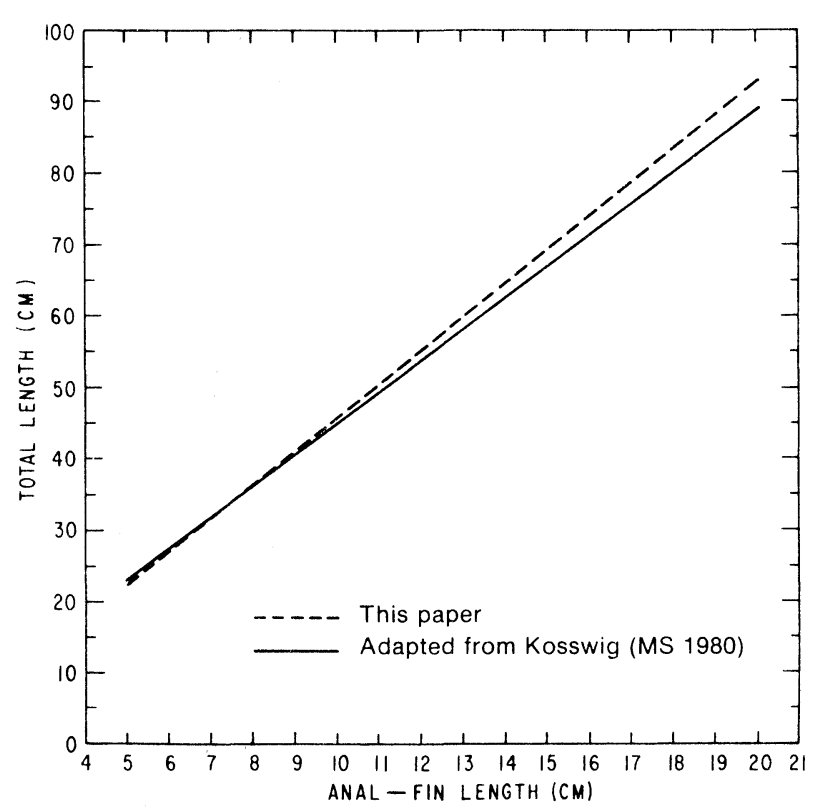

Fig. 4. Comparison of relationship between total length and anal-fin length for roundnose grenadier presented in this paper with that adapted from Kosswig (MS 1980).

storff and Koch, MS 1979; Kosswig, MS 1980) have consistently indicated the presence of a linear relationship between total length and pre-anus and/or anal-fin lengths, and the present study attests to its significance for roundnose grenadier in Div. $2 \mathrm{~J}$ and $3 \mathrm{~K}$ and, by inference, to the same species in the region from West Greenland to Newfoundland (Subareas 0, 1, 2 and 3). Messtorff and Koch (MS 1979) found a significant linear correlation between total length and preanus length for a grenadier, Macrourus whitsoni, on the Argentinian Shelf, perhaps indicating the applicability of the method of partial length measurements for grenadiers in general for all areas.

Because roundnose grenadier are usually caught at depths greater than $400 \mathrm{~m}$, distortion in the region of the anus is common when they are brought to the surface, due to air bladder expansion and extrusion of intestines through the anus. During the survey in 1979, the pre-anus length could not be recorded for a number of specimens due to the extent of this distortion. Also, in the case of shore-based sampling of gutted fish, the pre-anus length cannot be obtained leaving the anal-fin length as the only reliable measurement.

In the past, roundnose grenadier length frequencies have been reported as total length in 3-cm intervals. Since the ratio of anal-fin length to total length is approximately 0.215 , any new interval should be equivalent to or less than the product of this ratio and the previously used $3-\mathrm{cm}$ interval for total length. Thus the $0.5-\mathrm{cm}$ interval is considered to be the most appropriate one for reporting anal-fin length frequencies. 
Although pre-anus length and anal-fin length were both highly correlated with total length, because the pre-anus length may sometimes be affected by distortion of the anus, the Scientific Council of NAFO at its meeting in June 1980 recommended that the length measurements of roundnose grenadier, C. rupestris, and roughhead grenadier, Macrourus. berglax, should be reported as anal-fin length in $0.5-\mathrm{cm}$ intervals (NAFO, 1980).

\section{References}

ATKINSON, D. B. MS 1979. Roundnose grenadier stocks in ICNAF Subareas $0+1$ and 2+3. ICNAF Res. Doc., No. 57, Serial No. 5397. ICNAF. 1976. Report of Statistics and Sampling Subcommittee. ICNAF
Redbook 1976: 129-132.

1979. Report of Statistics and Sampling Subcommittee. ICNAF Redbook 1979: 93-96.

JENSEN, J. M. MS 1976. Length measurement of roundnose grenadier (Macrourus rupestris). ICNAF Res. Doc., No. 93, Serial No. 3913

KOSSWIG, K. MS 1980. A contribution on the age and growth of roundnose grenadier (Coryphaenoides rupestris Gunn) at West Greenland (NAFO Subarea 1). NAFO SCR Doc., No. 92, Serial No. N147.

MAXIM, C., I. PANAIT, and I. STAICU. MS 1979. Romanian research report, 1978. ICNAF Sum. Doc., No. 20, Serial No. 5431.

MESSTORFF, J., and K. H. KOCH. MS 1979. Relation of partial length measurements to total length with special reference to the sampling of grenadiers. ICNAF Res. Doc., No. 119, Serial No. 5486.

NAFO. 1980. Report of Scientific Council, Regular Meeting, June 1980. NAFO Sci. Coun. Rep., 1979-80: 63-70.

PARSONS, D. G., P. J. VEITCH, and W. E. LEGGE. MS 1978. Some characteristics of the roundnose grenadier fisheries in ICNAF Subareas 0+1 and 2+3. ICNAF Res. Doc., No. 47, Serial No. 5209 . 